\title{
CONNECTEDNESS IN SOFT m-STRUCTURE *
}

\author{
Samajh Singh Thakur and Alpa Singh Rajput
}

\begin{abstract}
In the present paper, we introduce the concept of soft connectedness in a soft m-structure and study some of its properties and characterizations.

Keywords: Soft m-structure, Soft m-connectedness and Soft m-connectedness between soft sets.
\end{abstract}

\section{Introduction}

The concept of soft set is fundamentally important in almost every scientific field. Soft set theory is a new mathematical tool dealing with uncertainty and has been applied in several directions since its introduction by Molodtsov [19] in 1999. The operations on soft sets and soft structures have been studied in [1, 16, 23]. Maji et. al [15] gave the first practical application of soft sets in decision theory. In 2011 Shabir and Naz [22] initiated a study of soft topological spaces. In recent years, many soft topological concepts such as soft connectedness and their strong forms $[8,11,17,20,24]$,soft separation axioms [14, 20, 22], weak and strong forms of soft open sets and soft continuity $[17,2,3,4,5,6,9,10,12,13,25]$ have been introduced and studied. Recently, the authors of this paper [21] initiated a study of soft mstructures. In the present paper we introduce the concept of soft connectedness in soft m-structures and we study some of its properties and characterizations.

\section{Preliminaries}

Let $\mathrm{U}$ be an initial universe set, $\mathrm{E}$ be a set of parameters, $\mathrm{P}(\mathrm{U})$ denote the power set of $\mathrm{U}$ and $\mathrm{A} \subseteq \mathrm{E}$.

Definition 2.1. [19] A pair (F, A) is called a soft set over $\mathrm{U}$, where $\mathrm{F}$ is a mapping given by $\mathrm{F}: \mathrm{A} \rightarrow \mathrm{P}(\mathrm{U})$. In other words, a soft set over $\mathrm{U}$ is a parameterized family of subsets of the universe U. For all $\mathrm{e} \in \mathrm{A}, \mathrm{F}(\mathrm{e})$ may be considered a set of eapproximate elements of the soft set (F, A).

Received December 07, 2016; accepted June 11, 2018.

2010 Mathematics Subject Classification. Primary 54A40, 54D10; Secondary 06D72

* The authors were supported in part by ... 
Definition 2.2. [16] For two soft sets (F, A) and (G, B) over a common universe $\mathrm{U}$, we say that $(\mathrm{F}, \mathrm{A})$ is a soft subset of $(\mathrm{G}, \mathrm{B})$, denoted by $(\mathrm{F}, \mathrm{A}) \subseteq(\mathrm{G}, \mathrm{B})$, if

(a) $\mathrm{A} \subseteq \mathrm{B}$ and

(b) $\mathrm{F}(\mathrm{e}) \subseteq \mathrm{G}$ (e) for all $\mathrm{e} \in \mathrm{E}$.

Definition 2.3. [16] Two soft sets (F, A) and (G, B) over a common universe $\mathrm{U}$ are said to be soft equal denoted by $(\mathrm{F}, \mathrm{A})=(\mathrm{G}, \mathrm{B})$ if $(\mathrm{F}, \mathrm{A}) \subseteq(\mathrm{G}, \mathrm{B})$ and $(\mathrm{G}, \mathrm{B})$ $\subseteq(\mathrm{F}, \mathrm{A})$.

Definition 2.4. [7] The complement of a soft set $(\mathrm{F}, \mathrm{A})$, denoted by $(F, A)^{c}$, is defined by $(F, A)^{c}=\left(F^{c}, \mathrm{~A}\right)$, where $F^{c}: \mathrm{A} \rightarrow \mathrm{P}(\mathrm{U})$ is a mapping given by $F^{c}(\mathrm{e})$ $=\mathrm{U}-\mathrm{F}(\mathrm{e})$, for all $\mathrm{e} \in \mathrm{E}$.

Definition 2.5. [16] Let a soft set (F, A) over U.

(a) A null soft set denoted by $\phi$ if for all e $\in \mathrm{A}, \mathrm{F}(\mathrm{e})=\phi$.

(b) An absolute soft set denoted by $\widetilde{U}$, if for each e $\in \mathrm{A}, \mathrm{F}(\mathrm{e})=\mathrm{U}$.

Clearly, $\widetilde{U}^{c}=\phi$ and $\phi^{c}=\widetilde{U}$.

Definition 2.6. [7] The union of two sets (F, A) and (G, B) over a common universe $\mathrm{U}$ is a soft set $(\mathrm{H}, \mathrm{C})$, where $\mathrm{C}=\mathrm{A} \cup \mathrm{B}$ and for all $\mathrm{e} \in \mathrm{C}$,

$$
H(e)= \begin{cases}F(e), & \text { ife } \in A-B \\ G(e), & \text { ife } \in B-A \\ F(e) \cup G(e), & \text { if } e \in A \cap B\end{cases}
$$

Definition 2.7. [7] The intersection of two soft sets (F, A) and $(\mathrm{G}, \mathrm{B})$ over a common universe $\mathrm{U}$ is a soft set $(\mathrm{H}, \mathrm{C})$ where $\mathrm{C}=\mathrm{A} \cap \mathrm{B}$ and $\mathrm{H}(\mathrm{e})=\mathrm{F}(\mathrm{e}) \cap \mathrm{G}(\mathrm{e})$ for each e $\in$ E.

Let $\mathrm{X}$ and $\mathrm{Y}$ be initial universe sets and $\mathrm{E}$ and $\mathrm{K}$ be non-empty sets of the parameters, $\mathrm{S}(\mathrm{X}, \mathrm{E})$ denotes the family of all soft sets over $\mathrm{X}$, and $\mathrm{S}(\mathrm{Y}, \mathrm{K})$ denotes the family of all soft sets over Y.

Definition 2.8. [12] Let $\mathrm{S}(\mathrm{X}, \mathrm{E})$ and $\mathrm{S}(\mathrm{Y}, \mathrm{K})$ be families of soft sets. Let $\mathrm{u}: \mathrm{X} \rightarrow$ $\mathrm{Y}$ and $\mathrm{p}: \mathrm{E} \rightarrow \mathrm{K}$ be mappings. Then a mapping $f_{p u}: \mathrm{S}(\mathrm{X}, \mathrm{E}) \rightarrow \mathrm{S}(\mathrm{Y}, \mathrm{K})$ is defined as:

(i)Let (F, A) be a soft set in $\mathrm{S}(\mathrm{X}, \mathrm{E})$. The image of (F, A) under $f_{p u}$, written as $f_{p u}(\mathrm{~F}, \mathrm{~A})=\left(f_{p u}(\mathrm{~F}), \mathrm{p}(\mathrm{A})\right)$, is a soft set in $\mathrm{S}(\mathrm{Y}, \mathrm{K})$ such that

$$
f_{p u}(F)(k)= \begin{cases}\bigcup_{e \in p^{-1}(k) \cap A} u(F(e)), & p^{-} 1(k) \bigcap A \neq \phi \\ \phi, & p^{-1}(k) \bigcap A=\phi\end{cases}
$$


For all $\mathrm{k} \in \mathrm{K}$.

(ii) Let $(\mathrm{G}, \mathrm{B})$ be a soft set in $\mathrm{S}(\mathrm{Y}, \mathrm{K})$. The inverse image of $(\mathrm{G}, \mathrm{B})$ under $f_{p u}$, written as $\left.f_{p u}^{-1}(\mathrm{G}, \mathrm{B})=\left(f_{p u}^{-1}(\mathrm{G}), p^{-1}(\mathrm{~B})\right)\right)$, is a soft set in $\mathrm{S}(\mathrm{X}, \mathrm{E})$ such that

$$
f_{p u}^{-1}(G)(e)= \begin{cases}u^{-1} G(p(e)), & p(e) \in B \\ \phi, & p(e) \notin B\end{cases}
$$

For all $\mathrm{e} \in \mathrm{E}$.

Definition 2.9. [25]Let $f_{p u}: \mathrm{S}(\mathrm{X}, \mathrm{E}) \rightarrow \mathrm{S}(\mathrm{Y}, \mathrm{K})$ be a mapping and $\mathrm{u}: \mathrm{X} \rightarrow \mathrm{Y}$ and $\mathrm{p}: \mathrm{E} \rightarrow \mathrm{K}$ be mappings. Then $f_{p u}$ is soft onto, if $\mathrm{u}: \mathrm{X} \rightarrow \mathrm{Y}$ and $\mathrm{p}: \mathrm{E} \rightarrow \mathrm{K}$ are onto and $f_{p u}$ is soft one-one, if $\mathrm{u}: \mathrm{X} \rightarrow \mathrm{Y}$ and $\mathrm{p}: \mathrm{E} \rightarrow \mathrm{K}$ are one-one.

Definition 2.10. [22] A subfamily $\tau$ of $\mathrm{S}(\mathrm{X}, \mathrm{E})$ is called a soft topology over $\mathrm{X}$ if:

1. $\widetilde{\phi}, \widetilde{X}$ belong to $\tau$.

2. The union of any number of soft sets in $\tau$ belongs to $\tau$.

3. The intersection of any two soft sets in $\tau$ belongs to $\tau$.

The triplet $(\mathrm{X}, \tau, \mathrm{E})$ is called a soft topological space over $\mathrm{X}$. The members of $\tau$ are called soft open sets in $\mathrm{X}$ and their complements are called soft closed sets in X.

Definition 2.11. If $(\mathrm{X}, \tau, \mathrm{E})$ is a soft topological space and a soft set $(\mathrm{F}, \mathrm{E})$ over $\mathrm{X}$.

(a) The soft closure of (F, E) is denoted by $\mathrm{Cl}(\mathrm{F}, \mathrm{E})$, and defined as the intersection of all soft closed super sets of (F,E) [22].

(b) The soft interior of $(\mathrm{F}, \mathrm{E})$ is denoted by $\operatorname{Int}(\mathrm{F}, \mathrm{E})$, and defined as the soft union of all soft open subsets of $(\mathrm{F}, \mathrm{E})[25]$.

Definition 2.12. [25] The soft set $(F, E) \in S(X, E)$ is called a soft point if there exist $\mathrm{x} \in \mathrm{X}$ and $\mathrm{e} \in \mathrm{E}$ such that $\mathrm{F}(\mathrm{e})=\{\mathrm{x}\}$ and $\mathrm{F}\left(\mathrm{e}^{\prime}\right)=\phi$ for each $\mathrm{e}^{\prime} \in \mathrm{E}-\{\mathrm{e}\}$, and the soft point $(\mathrm{F}, \mathrm{E})$ is denoted by $x_{e}$.

Definition 2.13. A soft set (A, E) of a soft topological space $(\mathrm{X}, \tau, \mathrm{E})$ is called :

(a) Soft regular open $(\mathrm{A}, \mathrm{E})=\operatorname{Int}(\mathrm{Cl}(\mathrm{A}, \mathrm{E}))[6]$;

(b) Soft $\alpha$-open if $(\mathrm{A}, \mathrm{E}) \subset \operatorname{Int}(\mathrm{Cl}(\operatorname{Int}(\mathrm{A}, \mathrm{E})))[3]$;

(c) Soft semi-open if $(\mathrm{A}, \mathrm{E}) \subset \mathrm{Cl}(\operatorname{Int}(\mathrm{A}, \mathrm{E}))[17]$;

(d) Soft preopen if $(\mathrm{A}, \mathrm{E}) \subset \operatorname{Int}(\mathrm{Cl}(\mathrm{A}, \mathrm{E}))[2]$;

(e) Soft b-open if $(\mathrm{A}, \mathrm{E}) \subset \operatorname{Int}(\mathrm{Cl}(\mathrm{A}, \mathrm{E})) \cup \mathrm{Cl}(\operatorname{Int}(\mathrm{A}, \mathrm{E}))$ [5]. 
(f) Soft $\beta$-open if $(\mathrm{A}, \mathrm{E}) \subset \mathrm{Cl}(\operatorname{Int}(\mathrm{Cl}(\mathrm{A}, \mathrm{E})))[4]$

The family of all soft regular open (resp. soft $\alpha$-open, soft semi-open, soft preopen, soft $\beta$-open, soft b-open) sets of $\mathrm{X}$ will be denoted by $\mathrm{SRO}(\mathrm{X}, \mathrm{E})$ (resp. $\mathrm{S} \alpha \mathrm{O}(\mathrm{X}, \mathrm{E}), \mathrm{SSO}(\mathrm{X}, \mathrm{E}), \mathrm{SPO}(\mathrm{X}, \mathrm{E}), \mathrm{S} \beta \mathrm{O}(\mathrm{X}, \mathrm{E}), \mathrm{SbO}(\mathrm{X}, \mathrm{E}))$.

Definition 2.14. Let $(\mathrm{A}, \mathrm{E})$ be a soft subset of a soft topological space $(\mathrm{X}, \tau, \mathrm{E})$. Then:

(a) The intersection of all soft semi-open sets containing (A, E) is called semiclosure of $(\mathrm{A}, \mathrm{E})$. It is denoted by $\mathrm{sCl}(\mathrm{A}, \mathrm{E})[17]$.

(b) The intersection of all soft preopen sets containing (A, E) is called preclosure of $(\mathrm{A}, \mathrm{E})$. It is denoted by $\mathrm{pCl}(\mathrm{A}, \mathrm{E})[2]$.

(c) The intersection of all soft $\alpha$ open sets containing $(\mathrm{A}, \mathrm{E})$ is called $\alpha$-closure of $(\mathrm{A}, \mathrm{E})$. It is denoted by $\alpha \mathrm{Cl}(\mathrm{A}, \mathrm{E})[3]$.

(d) The intersection of all soft b-open sets containing $(\mathrm{A}, \mathrm{E})$ is called b-closure of $(\mathrm{A}, \mathrm{E})$. It is denoted by $\mathrm{bCl}(\mathrm{A}, \mathrm{E})[5]$.

(e) The intersection of all soft $\beta$-open sets containing $(\mathrm{A}, \mathrm{E})$ is called $\beta$-closure of $(\mathrm{A}, \mathrm{E})$. It is denoted by $\beta \mathrm{Cl}(\mathrm{A}, \mathrm{E})[4]$.

Definition 2.15. A soft mapping $f_{p u}:(\mathrm{X}, \tau, \mathrm{E}) \rightarrow(\mathrm{X}, \sigma, \mathrm{K})$ is said to be :

(a) Soft continuous if $f_{p u}^{-1}(\mathrm{U}, \mathrm{K}) \in \tau$ for every soft set $(\mathrm{U}, \mathrm{K}) \in \sigma[25]$.

(b) Soft $\alpha$-continuous if $f_{p u}^{-1}(\mathrm{U}, \mathrm{K}) \in \mathrm{S} \alpha \mathrm{O}(\mathrm{X}, \mathrm{E})$ for every soft set $(\mathrm{U}, \mathrm{K}) \in \sigma[3]$.

(c) Soft semi-continuous if $f_{p u}^{-1}(\mathrm{U}, \mathrm{K}) \in \mathrm{SSO}(\mathrm{X}, \mathrm{E})$ for every soft set $(\mathrm{U}, \mathrm{K}) \in \sigma$ $[17]$.

(d) Soft precontinuous if $f_{p u}^{-1}(\mathrm{U}, \mathrm{K}) \in \mathrm{SPO}(\mathrm{X}, \mathrm{E})$ for every soft set $(\mathrm{U}, \mathrm{K}) \in \sigma$ $[2]$.

(e) Soft b-continuous if $f_{p u}^{-1}(\mathrm{U}, \mathrm{K}) \in \mathrm{SbO}(\mathrm{X}, \mathrm{E})$ for every soft set $(\mathrm{U}, \mathrm{K}) \in \sigma[5]$.

(f) Soft $\beta$-continuous if $f_{p u}^{-1}(\mathrm{U}, \mathrm{K}) \in \mathrm{S} \beta \mathrm{O}(\mathrm{X}, \mathrm{E})$ for every soft set $(\mathrm{U}, \mathrm{K}) \in \sigma[4]$.

Definition 2.16. A soft mapping $f_{p u}:(\mathrm{X}, \tau, \mathrm{E}) \rightarrow(\mathrm{X}, \sigma, \mathrm{K})$ is said to be :

(a) Soft open if $f_{p u}(\mathrm{U}, \mathrm{E}) \in \sigma$ for every soft set $(\mathrm{U}, \mathrm{E}) \in \tau[26]$.

(b) Soft $\alpha$-open if $f_{p u}(\mathrm{U}, \mathrm{E}) \in \mathrm{S} \alpha \mathrm{O}(\mathrm{Y}, \mathrm{K})$ for every soft set (U, E) $\in \tau$ [3].

(c) Soft semi-open if $f_{p u}(\mathrm{U}, \mathrm{E}) \in \mathrm{SSO}(\mathrm{Y}, \mathrm{K})$ for every soft set $(\mathrm{U}, \mathrm{E}) \in \tau$ [17].

(d) Soft preopen if $f_{p u}(\mathrm{U}, \mathrm{E}) \in \mathrm{SPO}(\mathrm{Y}, \mathrm{K})$ for every soft set $(\mathrm{U}, \mathrm{E}) \in \tau[2]$. 
(e) Soft b-open if $f_{p u}(\mathrm{U}, \mathrm{E}) \in \mathrm{SbO}(\mathrm{Y}, \mathrm{K})$ for every soft set (U, E) $\in \tau[5]$.

(f) Soft $\beta$-open if $f_{p u}(\mathrm{U}, \mathrm{E}) \in \mathrm{S} \beta \mathrm{O}(\mathrm{Y}, \mathrm{K})$ for every soft set $(\mathrm{U}, \mathrm{E}) \in \tau$ [4].

Definition 2.17. [14] Let $(\mathrm{X}, \tau, \mathrm{E})$ be a soft topological space, and $(\mathrm{A}, \mathrm{E}),(\mathrm{B}, \mathrm{E})$ be two soft sets over $\mathrm{X}$. The soft sets $(\mathrm{A}, \mathrm{E})$ and $(\mathrm{B}, \mathrm{E})$ are said to be soft-separated, if $(\mathrm{A}, \mathrm{E}) \cap \mathrm{Cl}(\mathrm{B}, \mathrm{E})=\phi$ and $\mathrm{Cl}(\mathrm{A}, \mathrm{E}) \cap(\mathrm{B}, \mathrm{E})=\phi$.

Definition 2.18. [14] Let $(\mathrm{X}, \tau, \mathrm{E})$ be a soft topological space and if there exist two non-empty soft separated sets $(\mathrm{A}, \mathrm{E}),(\mathrm{B}, \mathrm{E})$ such that $(\mathrm{A}, \mathrm{E}) \cup(\mathrm{B}, \mathrm{E})=\tilde{X}$, then $(\mathrm{A}, \mathrm{E})$ and $(\mathrm{B}, \mathrm{E})$ are said to be a soft disconnection for a soft topological space $(\mathrm{X}, \tau, \mathrm{E}) .(\mathrm{X}, \tau, \mathrm{E})$ is said to be soft-disconnected if $(\mathrm{X}, \tau, \mathrm{E})$ has a soft disconnection. Otherwise, $(\mathrm{X}, \tau, \mathrm{E})$ is said to be soft-connected.

Definition 2.19. [17] Let $(\mathrm{X}, \tau, \mathrm{E})$ be a soft topological space. The nonempty soft sets $(\mathrm{F}, \mathrm{A})$ and $(\mathrm{F}, \mathrm{B})$ in $\mathrm{S}(\mathrm{X}, \mathrm{E})$ are called soft semi-separated iff $\mathrm{sCl}(\mathrm{F}, \mathrm{A}) \cap(\mathrm{F}, \mathrm{B})$ $=(\mathrm{F}, \mathrm{A}) \cap \mathrm{sCl}(\mathrm{F}, \mathrm{B})=\phi$.

Definition 2.20. [17] Let $(\mathrm{X}, \tau, \mathrm{E})$ be a soft topological space. If there does not exist a soft semi-separation of $\mathrm{X}$, then it is said to be soft s-connected.

Definition 2.21. [24] Let $(\mathrm{X}, \tau, \mathrm{E})$ be a soft topological space. The nonempty soft sets $(\mathrm{F}, \mathrm{A})$ and $(\mathrm{F}, \mathrm{B})$ in $\mathrm{S}(\mathrm{X}, \mathrm{E})$ are called soft preseparated iff $\mathrm{pCl}(\mathrm{F}, \mathrm{A}) \cap(\mathrm{F}, \mathrm{B})=$ $(\mathrm{F}, \mathrm{A}) \cap \mathrm{pCl}(\mathrm{F}, \mathrm{B})=\phi$.

Definition 2.22. [24] Let $(\mathrm{X}, \tau, \mathrm{E})$ be a soft topological space. If there does not exist a soft preseparation of $\mathrm{X}$, then it is said to be soft $\mathrm{P}$-connected.

Definition 2.23. [21] A subfamily $m_{(X, E)}$ of $\mathrm{S}(\mathrm{X}, \mathrm{E})$ is called a soft minimal structure (briefly soft m-structure) over $\mathrm{X}$ if $\phi \in m_{(X, E)}$ and $\tilde{X} \in m_{(X, E)}$.

$\left(\mathrm{X}, m_{(X, E)}\right)$ is called a soft space with a soft minimal structure $m_{(X, E)}$ or simply a soft m-space. Each member of $m_{(X, E)}$ is called a soft m-open set and the complement of a soft m-open set is called a soft m-closed set.

Remark 2.1. [21] Let $(\mathrm{X}, \tau, \mathrm{E})$ be a soft topological space. Then the families $\tau, \mathrm{SSO}(\mathrm{X}, \mathrm{E})$, $\mathrm{SPO}(\mathrm{X}, \mathrm{E}), \mathrm{S} \alpha \mathrm{O}(\mathrm{X}, \mathrm{E}), \mathrm{S} \beta \mathrm{O}(\mathrm{X}, \mathrm{E}), \mathrm{S} b \mathrm{O}(\mathrm{X}, \mathrm{E}), \mathrm{SRO}(\mathrm{X}, \mathrm{E})$ are all soft m-structures over $\mathrm{X}$.

Definition 2.24. [21] Let $\mathrm{X}$ be a nonempty set, $\mathrm{E}$ be a set of parameters and $m_{(X, E)}$ be a soft $\mathrm{m}$-structure over $\mathrm{X}$. The soft $m_{(X, E)^{-}}$closure and the soft $m_{(X, E)^{-}}$ interior of the soft set $(\mathrm{A}, \mathrm{E})$ over $\mathrm{X}$ are defined as follows:

(1) $m_{(X, E)^{-}} \mathrm{Cl}(\mathrm{A}, \mathrm{E})=\cap\left\{(\mathrm{F}, \mathrm{E}):(\mathrm{A}, \mathrm{E}) \subset(\mathrm{F}, \mathrm{E}),(F, E)^{c} \in m_{(X, E)}\right\}$.

(2) $m_{(X, E)}-\operatorname{Int}(\mathrm{A}, \mathrm{E})=\cup\left\{(\mathrm{F}, \mathrm{E}):(\mathrm{F}, \mathrm{E}) \subset(\mathrm{A}, \mathrm{E}),(\mathrm{F}, \mathrm{E}) \in m_{(X, E)}\right\}$. 
Remark 2.2. [21] Let $(\mathrm{X}, \tau, \mathrm{E})$ be a soft topological space and $(\mathrm{A}, \mathrm{E})$ be a soft set over $\mathrm{X}$. If $m_{(X, E)}=\tau$ (respectively $\mathrm{SO}(\mathrm{X}, \mathrm{E}), \mathrm{SPO}(\mathrm{X}, \mathrm{E}), \mathrm{S} \alpha \mathrm{O}(\mathrm{X}, \mathrm{E}), \mathrm{S} \beta \mathrm{O}(\mathrm{X}, \mathrm{E}), \mathrm{S} b \mathrm{O}(\mathrm{X}, \mathrm{E})$ ), then we have:

(1) $m_{(X, E)}-\mathrm{Cl}(\mathrm{A}, \mathrm{E})=\mathrm{Cl}(\mathrm{A}, \mathrm{E})($ resp. $\mathrm{sCl}(\mathrm{A}, \mathrm{E}), \mathrm{pCl}(\mathrm{A}, \mathrm{E}), \alpha \mathrm{Cl}(\mathrm{A}, \mathrm{E}), \beta \mathrm{Cl}(\mathrm{A}, \mathrm{E}), \mathrm{bCl}(\mathrm{A}, \mathrm{E}))$.

(2) $m_{(X, E)}-\operatorname{Int}(\mathrm{A}, \mathrm{E})=\operatorname{Int}(\mathrm{A}, \mathrm{E})(\operatorname{resp} . \operatorname{sInt}(\mathrm{A}, \mathrm{E}), \operatorname{pInt}(\mathrm{A}, \mathrm{E}), \alpha \operatorname{Int}(\mathrm{A}, \mathrm{E}), \beta \operatorname{Int}(\mathrm{A}, \mathrm{E}), \operatorname{bInt}(\mathrm{A}, \mathrm{E}))$.

Theorem 2.1. [21] Let $S(X, E)$ be a family of soft sets and $m_{(X, E)}$ a soft minimal structure over $X$.

For soft sets $(A, E)$ and $(B, E)$ of $X$, the following holds:

(a) (i): $m_{(X, E)}-\operatorname{Int}(A, E)^{c}=\left(m_{(X, E)}-C l(A, E)\right)^{c}$ and (ii) : $m_{(X, E)}-C l(A, E)^{c}=$ $\left(m_{(X, E)}-\operatorname{Int}(A, E)\right)^{c}$.

(b) If $(A, E)^{c} \in m_{(X, E)}$, then $m_{(X, E)}-C l(A, E)=(A, E)$ and if $(A, E) \in m_{(X, E)}$ , then $m_{(X, E)}-\operatorname{Int}(A, E)=(A, E)$.

(c) $m_{(X, E)}-C l(\phi)=\phi, m_{(X, E)}-C l(\tilde{X})=\tilde{X}, m_{(X, E)}-\operatorname{Int}(\phi)=\phi, m_{(X, E)}-\operatorname{Int}(\tilde{X})=$ $\tilde{X}$.

(d) If $(A, E) \subset(B, E)$, then $m_{(X, E)}-C l(A, E) \subset m_{(X, E)}-C l(B, E), m_{(X, E)}-\operatorname{Int}(A, E)$ $\subset m_{(X, E)}-\operatorname{Int}(B, E)$.

(e) $(A, E) \subset m_{(X, E)}-C l(A, E)$ and $m_{(X, E)}-\operatorname{Int}(A, E) \subset(A, E)$.

(f) $m_{(X, E)}-C l\left(m_{(X, E)}-C l(A, E)\right)=m_{(X, E)}-C l(A, E)$ and $m_{(X, E)}-\operatorname{Int}\left(m_{(X, E)}-\operatorname{Int}(A, E)\right)$ $=m_{(X, E)}-\operatorname{Int}(A, E)$.

Definition 2.25. [21] A soft mapping $f_{p u}:\left(\mathrm{X}, m_{(X, E)}\right) \rightarrow\left(\mathrm{Y}, m_{(Y, K)}\right)$, where the minimal soft structure $m_{(X, E)}$ and $m_{(Y, K)}$ over X and Y, respectively, is said to be soft M-continuous if for each $x_{e} \in \mathrm{S}(\mathrm{X}, \mathrm{E})$ and each $(\mathrm{V}, \mathrm{K}) \in m_{(Y, K)}$ containing $f_{p u}$ $\left(x_{e}\right)$, there exists $(\mathrm{U}, \mathrm{E}) \in m_{(X, E)}$ containing $x_{e}$ such that $f_{p u}(\mathrm{U}, \mathrm{E}) \subset(\mathrm{V}, \mathrm{K})$.

Throughout this paper soft clopen means soft closed and open.

\section{Connectedness in soft m-structure}

Definition 3.1. [21] A soft minimal structure $m_{(X, E)}$ over $\mathrm{X}$ is said to have the property $\mathbf{B}$ if the union of any family of subsets belongs to $m_{(X, E)}$ belongs to $m_{(X, E)}$.

Definition 3.2. Let $\mathrm{X}$ be a nonempty set, $\mathrm{E}$ be a set of parameters and $m_{(X, E)}$ be a soft $\mathrm{m}$-structure over $\mathrm{X}$ with property $\mathbf{B}$. In $\left(\mathrm{X}, m_{(X, E)}\right)$ two nonempty soft sets $(\mathrm{A}, \mathrm{E})$ and $(\mathrm{B}, \mathrm{E})$ over $\mathrm{X}$ are called soft m-separated iff $m_{(X, E)}-\mathrm{Cl}(\mathrm{A}, \mathrm{E}) \cap(\mathrm{B}, \mathrm{E})$ $=(\mathrm{A}, \mathrm{E}) \cap m_{(X, E)}-\mathrm{Cl}(\mathrm{B}, \mathrm{E})=\phi$. 
Remark 3.1. Let $(\mathrm{X}, \tau, \mathrm{E})$ be a soft topological space over X. If $m_{(X, E)}=\tau$ (resp. $\mathrm{SSO}(\mathrm{X}, \mathrm{E}), \mathrm{SPO}(\mathrm{X}, \mathrm{E}), \mathrm{SbO}(\mathrm{X}, \mathrm{E}))$ and $m_{(X, E)}-\mathrm{Cl}(\mathrm{A}, \mathrm{E})=\mathrm{Cl}(\mathrm{A}, \mathrm{E})$ (resp. sCl(A,E), $\mathrm{pCl}(\mathrm{A}, \mathrm{E}), \mathrm{bCl}(\mathrm{A}, \mathrm{E})$ ) we get definitions of soft separated( resp. soft semi-separated, soft preseparated, soft b-separated) sets.

Definition 3.3. Let $m_{(X, E)}$ be a soft m-structure over $\mathrm{X}$ with the property $\mathbf{B}$. Then $\left(\mathrm{X}, m_{(X, E)}\right)$ is said to be soft $\mathrm{m}$-connected if there does not exist two nonempty soft m-separated sets $(\mathrm{A}, \mathrm{E})$ and $(\mathrm{B}, \mathrm{E})$ over $\mathrm{X}$, such that $(\mathrm{A}, \mathrm{E}) \cup(\mathrm{B}, \mathrm{E})=\tilde{X}$. Otherwise it is soft $\mathrm{m}$-disconnected. In this case, the pair $(\mathrm{A}, \mathrm{E})$ and $(\mathrm{B}, \mathrm{E})$ is called soft m-disconnection over X.

Remark 3.2. Let $(\mathrm{X}, \tau, \mathrm{E})$ be a soft topological space over $\mathrm{X}$. If we replace soft $\mathrm{m}$ separated by soft separated (resp. soft semi-separated, soft preseparated, soft b-separated) sets we get a definition for soft connectedness (resp. soft semi-connectedness, soft preconnectedness, soft b-connectedness).

Theorem 3.1. Let $\left(X, m_{(X, E)}\right)$ be a soft m-space with the property $\mathbf{B}$. Then the following conditions are equivalent:

(1) $\left(X, m_{(X, E)}\right)$ has a soft m-disconnection.

(2) There exist two disjoint soft $m$-closed sets $(A, E),(B, E) \in m_{(X, E)}$ such that $(A, E) \cup(B, E)=\tilde{X}$.

(3) There exist two disjoint soft m-open sets $(A, E),(B, E) \in m_{(X, E)}$ such that $(A, E) \cup(B, E)=\tilde{X}$.

(4) $\left(X, m_{(X, E)}\right)$ has a proper soft $m$-open and soft $m$-closed set over $X$.

Proof: $(1) \rightarrow(2):$ Let $\left(\mathrm{X}, m_{(X, E)}\right)$ have a soft m-disconnection $(\mathrm{A}, \mathrm{E})$ and $(\mathrm{B}, \mathrm{E})$. Then $(\mathrm{A}, \mathrm{E}) \cap(\mathrm{B}, \mathrm{E})=\phi$ and

$$
m_{(X, E)}-\mathrm{Cl}(\mathrm{A}, \mathrm{E})=m_{(X, E)^{-}} \mathrm{Cl}(\mathrm{A}, \mathrm{E}) \cap((\mathrm{A}, \mathrm{E}) \cup(\mathrm{B}, \mathrm{E}))=\left(m_{(X, E)}-\mathrm{Cl}(\mathrm{A}, \mathrm{E}) \cap\right.
$$
$(\mathrm{A}, \mathrm{E})) \cup\left(m_{(X, E)^{-}} \mathrm{Cl}(\mathrm{A}, \mathrm{E}) \cap(\mathrm{B}, \mathrm{E})\right)=(\mathrm{A}, \mathrm{E})$.

Therefore, $(\mathrm{A}, \mathrm{E})$ is a soft $\mathrm{m}$-closed set over $\mathrm{X}$. Similarly, we can see that $(\mathrm{B}, \mathrm{E})$ is also a soft $\mathrm{m}$-closed set over X.

$(2) \rightarrow(3)$ : Let $\left(\mathrm{X}, m_{(X, E)}\right)$ has a soft m-disconnection $(\mathrm{A}, \mathrm{E})$ and $(\mathrm{B}, \mathrm{E})$ such that $(\mathrm{A}, \mathrm{E})$ and $(\mathrm{B}, \mathrm{E})$ are soft $\mathrm{m}$-closed. Then $(A, E)^{c}$ and $(B, E)^{c}$ are soft $\mathrm{m}$-open sets in $m_{(X, E)}$. Then it is easy to see $(A, E)^{c} \cap(B, E)^{c}=\phi$ and $(A, E)^{c} \cup(B, E)^{c}$ $=\tilde{X}$.

$(3) \rightarrow(4)$ : Let $\left(\mathrm{X}, m_{(X, E)}\right)$ have a soft m-disconnection $(\mathrm{A}, \mathrm{E})$ and $(\mathrm{B}, \mathrm{E})$ such that $(\mathrm{A}, \mathrm{E})$ and $(\mathrm{B}, \mathrm{E})$ are soft $\mathrm{m}$-open over $\mathrm{X}$. Then $(\mathrm{A}, \mathrm{E})$ and $(\mathrm{B}, \mathrm{E}$ are also soft closed in $\left(\mathrm{X}, m_{(X, E)}\right)$.

$(4) \rightarrow(1)$ : Let $\left(\mathrm{X}, m_{(X, E)}\right)$ has a proper soft m-open and soft m-closed set $(\mathrm{F}, \mathrm{E})$ over X. Put $(\mathrm{H}, \mathrm{E})=(F, E)^{c}$. Then $(\mathrm{H}, \mathrm{E})$ and $(\mathrm{F}, \mathrm{E})$ are non-empty soft m-closed sets in $\left(\mathrm{X}, m_{(X, E)}\right)$. $(\mathrm{H}, \mathrm{E}) \cap(\mathrm{F}, \mathrm{E})=\phi$ and $(\mathrm{H}, \mathrm{E}) \cup(\mathrm{F}, \mathrm{E})=\tilde{X}$. Therefore, $(\mathrm{H}, \mathrm{E})$ and $(\mathrm{F}, \mathrm{E})$ is a soft m-disconnection of $\left(\mathrm{X}, m_{(X, E)}\right)$. 
Remark 3.3. Let $(\mathrm{X}, \tau, \mathrm{E})$ be a soft topological space over $\mathrm{X}$, if $m_{(X, E)}=\tau$ (resp. $\mathrm{SSO}(\mathrm{X}, \mathrm{E}), \mathrm{SPO}(\mathrm{X}, \mathrm{E}), \mathrm{SbO}(\mathrm{X}, \mathrm{E}))$ Then the following conditions are equivalent:

(1) $(\mathrm{X}, \tau, \mathrm{E})$ has a soft disconnection (resp. soft semi-disconnection, soft pre disconnection, soft b-disconnection).

(2) There exist two disjoint soft closed (resp. soft semi-closed, soft pre-closed, soft b-closed) sets $(\mathrm{A}, \mathrm{E}),(\mathrm{B}, \mathrm{E})$ such that $(\mathrm{A}, \mathrm{E}) \cup(\mathrm{B}, \mathrm{E})=\tilde{X}$.

(3) There exist two disjoint soft open (resp. soft semi-open, soft pre-open, soft b-open) sets $(\mathrm{A}, \mathrm{E}),(\mathrm{B}, \mathrm{E})$ such that $(\mathrm{A}, \mathrm{E}) \cup(\mathrm{B}, \mathrm{E})=\tilde{X}$.

(4) $(\mathrm{X}, \tau, \mathrm{E})$ has a proper soft open(resp. soft semi-open, soft pre-open, soft b-open) and soft closed (resp. soft semi-closed, soft pre-closed, soft b-closed) set over X.

Corollary 3.1. Let $\left(X, m_{(X, E)}\right)$ be a soft $m$-space with the property $\mathbf{B}$. Then the following conditions are equivalent: (1) $\left(X, m_{(X, E)}\right)$ is a soft m-connected.

(2) There does not exist two disjoint soft $m$-closed sets $(A, E),(B, E) \in m_{(X, E)}$ such that $(A, E) \cup(B, E)=\tilde{X}$.

(3) There does not exist two disjoint soft m-open sets $(A, E),(B, E) \in m_{(X, E)}$ such that $(A, E) \cup(B, E)=\tilde{X}$.

(4) $\left(X, m_{(X, E)}\right)$ at most has two soft $m$-closed and soft m-open sets over $X$, that is, $\phi$ and $\tilde{X}$.

Remark 3.4. Let $(\mathrm{X}, \tau, \mathrm{E})$ be a soft topological space over $\mathrm{X}$, if $m_{(X, E)}=\tau$ (resp. $\mathrm{SSO}(\mathrm{X}, \mathrm{E}), \mathrm{SPO}(\mathrm{X}, \mathrm{E}), \mathrm{SbO}(\mathrm{X}, \mathrm{E}))$. Then the following conditions are equivalent:

(1) $(\mathrm{X}, \tau, \mathrm{E})$ is a soft connected (resp. soft semi-connected, soft preconnected ,soft $\mathrm{b}$-connected).

(2) There does not exist two disjoint soft closed (resp. soft semi-closed, soft preclosed, soft b-closed) sets $(\mathrm{A}, \mathrm{E}),(\mathrm{B}, \mathrm{E})$ such that $(\mathrm{A}, \mathrm{E}) \cup(\mathrm{B}, \mathrm{E})=\tilde{X}$.

(3) There does not exist two disjoint soft open (resp. soft semi-open, soft pre-open, soft b-open) sets $(\mathrm{A}, \mathrm{E}),(\mathrm{B}, \mathrm{E})$ such that $(\mathrm{A}, \mathrm{E}) \cup(\mathrm{B}, \mathrm{E})=\tilde{X}$.

(4) $(\mathrm{X}, \tau, \mathrm{E})$ has a proper soft open(resp. soft semi-open, soft pre-open, soft b-open) and soft closed (resp. soft semi-closed, soft pre-closed, soft b-closed)set over X.

Definition 3.4. Let $\left(\mathrm{X}, m_{(X, E)}\right)$ be a soft m-space with the property $\mathbf{B}, \mathrm{Y} \subset \mathrm{X}$ in $\left(\mathrm{X}, m_{(X, E)}\right)$. The soft space $\left(\mathrm{Y}, m_{(Y, E)}\right)$ is called a soft m-subspace of $\left(\mathrm{X}, m_{(X, E)}\right)$ if $m_{(Y, E)}=\left\{(\mathrm{A}, \mathrm{E}) \cap \tilde{Y}:(\mathrm{A}, \mathrm{E}) \in m_{(X, E)}\right\}$.

Lemma 3.1. Let $\left(X, m_{(X, E)}\right)$ be a soft m-space with the property $\mathbf{B},\left(Y, m_{(Y, E)}\right)$ be a soft m-subspace of $\left(X, m_{(X, E)}\right)$. If $(A, E) \subset \tilde{Y} \subset \tilde{X}$. Then $m_{(Y, E)}-C l(A, E)=$ $m_{(X, E)}-C l(A, E) \cap \tilde{Y}$.

Proof: We have $\left.m_{(Y, E)}-\mathrm{Cl}(\mathrm{A}, \mathrm{E})=\cap\left\{(\mathrm{F}, \mathrm{E}):(\mathrm{A}, \mathrm{E}) \subset(\mathrm{F}, \mathrm{E}), \tilde{Y}-(\mathrm{F}, \mathrm{E}) \in m_{(Y, E)}\right)\right\}=$ $\left.\cap\left\{(\mathrm{F}, \mathrm{E}) \cap \tilde{Y}:(\mathrm{A}, \mathrm{E}) \subset(\mathrm{F}, \mathrm{E}) \cap \tilde{Y}, \tilde{X}-(\mathrm{F}, \mathrm{E}) \in m_{(X, E)}\right)\right\}=\cap\{(\mathrm{F}, \mathrm{E}) \cap \tilde{Y}:(\mathrm{A}, \mathrm{E}) \subset$ $\left.\left.(\mathrm{F}, \mathrm{E}), \tilde{X}-(\mathrm{F}, \mathrm{E}) \in m_{(X, E)}\right)\right\}=\cap\left\{(\mathrm{F}, \mathrm{E}):(\mathrm{A}, \mathrm{E}) \subset(\mathrm{F}, \mathrm{E}), \tilde{X}-(\mathrm{F}, \mathrm{E}) \in m_{(X, E)}\right\} \cap$ $\tilde{Y}=m_{(X, E)}-\mathrm{Cl}(\mathrm{A}, \mathrm{E}) \cap \tilde{Y}$.

Therefore, the lemma holds. 
Lemma 3.2. Let $\left(X, m_{(X, E)}\right)$ be a soft m-space with the property $\mathbf{B},\left(Y, m_{(Y, E)}\right)$ be a soft m-subspace of $\left(X, m_{(X, E)}\right)$. If $(A, E)$ and $(B, E)$ are soft sets in $\left(Y, m_{(Y, E)}\right)$, then $(A, E)$ and $(B, E)$ are soft $m$-separated in $\left(Y, m_{(Y, E)}\right)$ if and only if $(A, E)$ and $(B, E)$ are soft $m$-separated in $\left(X, m_{(X, E)}\right)$.

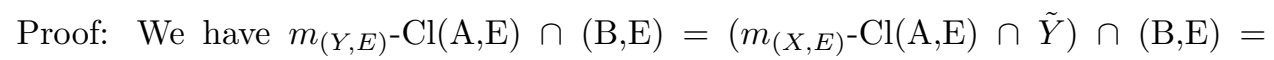
$m_{(X, E)}-\mathrm{Cl}(\mathrm{A}, \mathrm{E}) \cap(\mathrm{B}, \mathrm{E})$ by lemma 3.1 .

Similarly, we have

$m_{(Y, E)}-\mathrm{Cl}(\mathrm{B}, \mathrm{E}) \cap(\mathrm{A}, \mathrm{E})=m_{(X, E)}-\mathrm{Cl}(\mathrm{B}, \mathrm{E}) \cap(\mathrm{A}, \mathrm{E})$.

Therefore, the lemma holds.

Lemma 3.3. Let $\left(X, m_{(X, E)}\right)$ be a soft $m$-space with the property $\mathbf{B}, \tilde{Y} \subset \tilde{X}$.

$\left(Y, m_{(Y, E)}\right)$ be a soft m-subspace of $\left(X, m_{(X, E)}\right) .\left(Y, m_{(Y, E)}\right)$ is soft m-connected. If $(A, E)$ and $(B, E)$ are soft $m$-separated in $\left(X, m_{(X, E)}\right)$, such that $\tilde{Y} \subset(A, E) \cup(B, E)$, then $\tilde{Y} \subset(A, E)$ or $\tilde{Y} \subset(B, E)$.

Proof: We have $\tilde{Y} \subset(A, E) \cup(B, E)$, we have $\tilde{Y}=(\tilde{Y} \cap(A, E)) \cup(\tilde{Y} \cap(B, E))$. By lemma 3.2 , $\tilde{Y} \cap(A, E)$ and $\tilde{Y} \cap(B, E)$ are soft m-separated in $\left(Y, m_{(Y, E)}\right)$. Since $\left(Y, m_{(Y, E)}\right)$ is soft m-connected, we have $\tilde{Y} \cap(A, E)=\phi$ or $\tilde{Y} \cap(B, E)=\phi$. Therefore, $\tilde{Y} \subset(A, E)$ or $\tilde{Y} \subset(B, E)$.

Lemma 3.4. Let $\left\{\left(X_{\alpha}, m_{\left(X_{\alpha}, E\right)}: \alpha \in J\right\}\right.$ be a soft family non-empty soft mconnected subspaces of $\left(X, m_{(X, E)}\right)$. If $\bigcap_{\alpha \in J} X_{\alpha} \neq \phi$, then $\left(\cup_{\alpha \in J} X_{\alpha}, \cup_{\alpha \in J} m_{\left(X_{\alpha}, E\right)}\right.$ is a soft m-connected subspace of $\left(X, m_{(X, E)}\right)$.

Proof: Let $Y=\left(\bigcup_{\alpha \in J} X_{\alpha}\right)$. Choose a soft point $x_{e} \in \tilde{Y}$. Let $(C, E)$ and $(D, E)$ be a soft m-disconnection of $\left(\cup_{\alpha \in J} X_{\alpha}, \cup_{\alpha \in J} m_{\left(X_{\alpha}, E\right)}\right.$. Then, $x_{e} \in(C, E)$ and $x_{e} \in$ $(D, E)$, we assume that $x_{e} \in(C, E)$. For each $\alpha \in J$. Since $\left\{\left(X_{\alpha}, m_{\left(X_{\alpha}, E\right)}\right.\right.$ is soft $m$-connected, it follows from lemma 3.3 that $\left.\tilde{(} X_{\alpha}\right) \subset(C, E)$ or $\left.\tilde{(} X_{\alpha}\right) \subset(D, E)$. Therefore, we have $\tilde{Y} \subset(C, E)$ since $x_{e} \in(C, E)$ and then $(D, E)=\phi$, which is a contradiction. Thus $\left(\cup_{\alpha \in J} X_{\alpha}, \cup_{\alpha \in J} m_{\left(X_{\alpha}, E\right.}\right)$ is a soft m-connected subspace of $\left(X, m_{(X, E)}\right)$.

Theorem 3.2. Let $\left\{\left(X_{\alpha}, m_{\left(X_{\alpha}, E\right)}\right): \alpha \in J\right\}$ be a soft family non-empty soft mconnected subspaces of $\left(X, m_{(X, E)}\right)$.If $X_{\alpha} \cap X_{\beta} \neq \phi$ for $\alpha, \beta \in J$, then $\left(\cup_{\alpha \in J} X_{\alpha}, m_{\left(\cup_{\alpha \in J} X_{\alpha}, E\right)}\right)$ is a soft m-connected subspace of $\left(X, m_{(X, E)}\right)$.

Proof : Let $\alpha_{o} \in \mathrm{J}$. For $\beta \in \mathrm{J}, \mathrm{Put} A_{\beta}=X_{\alpha_{o}} \cup X_{\beta}$ By lemma 3.4, $\left\{\left(A_{\beta}, m_{\left(X_{\beta}, E\right)}\right.\right.$ is soft m-connected. Then, $\left\{\left\{\left(A_{\beta}, m_{\left(X_{\beta}, E\right)}: \beta \in J\right\}\right.\right.$ is a family soft m-connected subspace of $\left(\mathrm{X}, m_{(X, E)}\right)$ and $\bigcap_{\beta \in J} A_{\beta}=X_{\alpha_{o}} \neq \phi$. Obviously, $\left(\bigcup_{\alpha \in J} X_{\alpha}=\left(\bigcup_{\beta \in J} A_{\beta}\right.\right.$. It follows from lemma 3.4 that $\left(\cup_{\alpha \in J} X_{\alpha}, \cup_{\alpha \in J} m_{\left(X_{\alpha}, E\right)}\right.$ is a soft m-connected subspace of $\left(\mathrm{X}, m_{(X, E)}\right)$.

Theorem 3.3. Let $\left(X, m_{(X, E)}\right)$ be a soft m-space with the property $\mathbf{B}, \tilde{Y} \subset \tilde{X}$. $\left(Y, m_{(Y, E)}\right)$ be a soft m-subspace of $\left(X, m_{(X, E)}\right)$. If $\tilde{Y} \subset \tilde{A} \subset m_{(X, E)}-C l(F, E)$, then 
$\left(A, m_{(A, E)}\right)$ is a soft connected m-subspace of $\left(X, m_{(X, E)}\right)$. In particular, $m_{(X, E)^{-}}$ $C l(F, E)$ is a soft connected m-subspace of $\left(X, m_{(X, E)}\right)$.

Proof: Let $(C, E)$ and $(D, E)$ be a soft m-disconnection of $\left(A, m_{(A, E)}\right)$. By lemma 3.3, we have $\tilde{A} \subset(C, E)$ or $\tilde{A} \subset(D, E)$. We assume that $\tilde{A} \subset(C, E)$. By lemma 3.2, we have $m_{(X, E)}-C l(C, E) \cap(D, E)=\phi$ and, hence, $\tilde{A} \cap(D, E)=\phi$, which is a contradiction.

Theorem 3.4. Let $f_{p u}:\left(X, m_{(X, E)}\right) \rightarrow\left(Y, m_{(Y, K)}\right)$ be a soft M-continuous mapping, where $m_{(X, E)}$ and $m_{(Y, K)}$ are soft minimal structures over $X$ and $Y$, respectively. If $\left(X, m_{(X, E)}\right)$ is soft $m$-connected, then the soft image of $\left(X, m_{(X, E)}\right)$ is also soft m-connected.

Proof: Let $f_{p u}:\left(\mathrm{X}, m_{(X, E)}\right) \rightarrow\left(\mathrm{Y}, m_{(Y, K)}\right)$ be a soft continuous mapping. Conversely, suppose that $\left(\mathrm{Y}, m_{(Y, K)}\right)$ is soft m-disconnected and the pair $(\mathrm{A}, \mathrm{K})$ and $(\mathrm{B}, \mathrm{K})$ is a soft $\mathrm{m}$-disconnection of $\left(\mathrm{Y}, m_{(Y, K)}\right)$. Since $f_{p u}:\left(\mathrm{X}, m_{(X, E)}\right) \rightarrow\left(\mathrm{Y}, m_{(Y, K)}\right)$ is soft continuous, then $f_{p u}^{-1}(\mathrm{~A}, \mathrm{~K}) \in m_{(X, E)}, f_{p u}^{-1}(\mathrm{~B}, \mathrm{~K}) \in m_{(X, E)}$. Clearly, the pair $f_{p u}^{-1}(\mathrm{~A}, \mathrm{~K})$ and $f_{p u}^{-1}(\mathrm{~B}, \mathrm{~K})$ is a soft m-disconnection of $\left(\mathrm{X}, m_{(X, E)}\right)$, which is a contradiction. Hence, $\left(\mathrm{Y}, m_{(Y, K)}\right)$ is soft m-connected. This completes the proof.

Remark 3.5. Let $(\mathrm{X}, \tau, \mathrm{E})$ and $(\mathrm{Y}, \vartheta, \mathrm{K})$ be two soft topological spaces over $\mathrm{X}$ and $\mathrm{Y}$, respectively. If $m_{(X, E)}=\tau, m_{(Y, K)}=\vartheta . \quad f_{p u}:(\mathrm{X}, \tau, \mathrm{E}) \rightarrow(\mathrm{Y}, \vartheta, \mathrm{K})$ is a soft continuous mapping. If $(\mathrm{X}, \tau, \mathrm{E})$ is soft connected (resp. soft semi-connected, soft pre connected, soft b-connected) then the soft image of $(\mathrm{X}, \tau, \mathrm{E})$ is also soft connected (resp. soft semiconnected, soft preconnected, soft b-connected).

Definition 3.5. Let $m_{(X, E)}$ be a soft m-structure over X. A soft set (F,E) in $\left(\mathrm{X}, m_{(X, E)}\right)$ is soft $\mathrm{m}$-connected if it is soft $\mathrm{m}$-connected as a soft $\mathrm{m}$-subspace.

Remark 3.6. Let $(\mathrm{X}, \tau, \mathrm{E})$ be a soft topological space over $\mathrm{X}$. A soft set $(\mathrm{F}, \mathrm{E})$ in $(\mathrm{X}, \tau, \mathrm{E})$ is soft connected (resp. soft semi-connected, soft preconnected and soft b-connected) if it is soft connected (resp. soft semi-connected, soft preconnected and soft b-connected) as a soft subspace.

Theorem 3.5. Let $m_{(X, E)}$ be a soft m-structure over $X,(G, E)$ be a soft $m$ connected set in $\left(X, m_{(X, E)}\right)$ and $(F, E)$ be a soft set over $X$ such that $(G, E) \subset$ $(F, E) \subset m_{(X, E)}-C l(G, E)$. Then $(F, E)$ is soft m-connected.

Proof: It is sufficient that $m_{(X, E)}-\mathrm{Cl}(\mathrm{G}, \mathrm{E})$ is soft m-connected. On the contrary, suppose that $m_{(X, E)}-\mathrm{Cl}(\mathrm{G}, \mathrm{E})$ is soft m-disconnected. Then there exists a soft m-disconnection $((\mathrm{H}, \mathrm{E}),(\mathrm{K}, \mathrm{E}))$ of $m_{(X, E)}-\mathrm{Cl}(\mathrm{G}, \mathrm{E})$. That is, there are $((\mathrm{H}, \mathrm{E}) \cap$ $(\mathrm{G}, \mathrm{E})),((\mathrm{K}, \mathrm{E}) \cap(\mathrm{G}, \mathrm{E}))$ soft sets in $(\mathrm{G}, \mathrm{E})$ such that $((\mathrm{H}, \mathrm{E}) \cap(\mathrm{G}, \mathrm{E})) \cap((\mathrm{K}, \mathrm{E}) \cap(\mathrm{G}, \mathrm{E}))$ $=((\mathrm{H}, \mathrm{E}) \cap(\mathrm{K}, \mathrm{E})) \cap(\mathrm{G}, \mathrm{E})=\phi$, and $((\mathrm{H}, \mathrm{E}) \cap(\mathrm{G}, \mathrm{E})) \cup((\mathrm{K}, \mathrm{E}) \cap(\mathrm{G}, \mathrm{E}))=((\mathrm{H}, \mathrm{E}) \cup$ $(\mathrm{K}, \mathrm{E})) \cap(\mathrm{G}, \mathrm{E})=(\mathrm{G}, \mathrm{E})$. This yields that the pair $((\mathrm{H}, \mathrm{E}) \cap(\mathrm{G}, \mathrm{E}))$ and $((\mathrm{K}, \mathrm{E}) \cap$ $(\mathrm{G}, \mathrm{E})$ ) is a soft m-disconnection of $(\mathrm{G}, \mathrm{E})$, which is a contradiction. This proves that $m_{(X, E)}-\mathrm{Cl}(\mathrm{G}, \mathrm{E})$ is soft $\mathrm{m}$-connected. Hence, the proof is complete. 
Lemma 3.5. Let $m_{(X, E)}$ be a soft m-structure over $X$ with the property $\mathbf{B}$, and let $(A, E)$ and $(B, E)$ be two soft sets over $X$. In $\left(X, m_{(X, E)}\right)$ the following statements are equivalent:

(1) $\phi, \tilde{X}$ are only soft $m$-open and soft $m$-closed set in $m_{(X, E)}$.

(2) $\left(X, m_{(X, E)}\right)$ is not a soft union of two disjoint soft sets $(A, E)$ and $(B, E) \in$ $m_{(X, E)}$.

(3) $\left(X, m_{(X, E)}\right)$ is not a soft union of two disjoint soft sets $(A, E)^{c}$ and $(B, E)^{c}$ $\in m_{(X, E)}$.

$(4)\left(X, m_{(X, E)}\right)$ is not a soft union of two nonempty soft m-separated sets.

Remark 3.7. Let $\left(\mathrm{X}, \tau\right.$, E) be a soft topological space over $\mathrm{X}$, so we put $m_{(X, E)}=\tau$ (resp. $\mathrm{SSO}(\mathrm{X}, \mathrm{E}), \mathrm{SPO}(\mathrm{X}, \mathrm{E}), \mathrm{SbO}(\mathrm{X}, \mathrm{E})$ ). Also, let $(\mathrm{A}, \mathrm{E})$ and $(\mathrm{B}, \mathrm{E})$ be two soft sets over $\mathrm{X}$. In $(\mathrm{X}, \tau, \mathrm{E})$ the following statements are equivalent:

(1) $\phi$ and $\tilde{X}$ are only soft clopen (resp. soft semi-clopen, soft preclopen, soft b-clopen) sets in $(\mathrm{X}, \tau, \mathrm{E})$.

(2) $(\mathrm{X}, \tau, \mathrm{E})$ is not a soft union of two soft disjoint soft open(resp. soft semi-open ,soft pre open, soft b-open) sets .

(3) $(\mathrm{X}, \tau, \mathrm{E})$ is not a soft union of two soft disjoint soft closed (resp. soft semi-closed, soft preclosed, soft b-closed) sets.

(4) $(\mathrm{X}, \tau, \mathrm{E})$ is not a soft union of two nonempty soft separated(soft semi separated, soft preseparated, soft b-separated) sets.

Theorem 3.6. Let $m_{(X, E)}$ be a soft m-structure over $X$ with the property $\mathbf{B}$. In $\left(X, m_{(X, E)}\right)$ the following statements are equivalent:

(1) $\left(X, m_{(X, E)}\right)$ is a soft m-connected space.

(2) $\left(X, m_{(X, E)}\right)$ is not a soft union of any two soft m-separated sets.

Proof : $(1) \rightarrow(2)$ : Assume (1). Suppose (2) is false, then let (A,E) and (B,E) be two soft $\mathrm{m}$-separated sets such that $\tilde{X}=(\mathrm{A}, \mathrm{E}) \cup(\mathrm{B}, \mathrm{E})$. Since $\left(\mathrm{X}, m_{(X, E)}\right)$ is soft m-connected $m_{(X, E)}-\mathrm{Cl}(\mathrm{A}, \mathrm{E}) \cap(\mathrm{B}, \mathrm{E})=(\mathrm{A}, \mathrm{E}) \cap m_{(X, E)}-\mathrm{Cl}(\mathrm{B}, \mathrm{E})=\phi$. Since $(\mathrm{A}, \mathrm{E})$ $\subset m_{(X, E)}-\mathrm{Cl}(\mathrm{A}, \mathrm{E})$ and $(\mathrm{B}, \mathrm{E}) \subset m_{(X, E)}-\mathrm{Cl}(\mathrm{B}, \mathrm{E})$, then $(\mathrm{A}, \mathrm{E}) \cup(\mathrm{B}, \mathrm{E})=\phi$. Now $m_{(X, E)} \mathrm{Cl}(\mathrm{A}, \mathrm{E}) \subset(B, E)^{c}=(\mathrm{A}, \mathrm{E})$. Hence, $m_{(X, E)} \mathrm{Cl}(\mathrm{A}, \mathrm{E})=(\mathrm{A}, \mathrm{E})$. Therefore, $(A, E)^{c} \in m_{(X, E)}$. By the same way we show that $(B, E)^{c} \in m_{(X, E)}$ which is a contradiction with remark 3.5. This shows that (2) is true. Therefore $(1) \rightarrow(2)$.

$(2) \rightarrow(1)$ : Assume that $(2)$ is not true. Let $(A, E)^{c}$ and $(B, E)^{c}$ be two soft m-disjoint nonempty and $(A, E)^{c}$ and $(B, E)^{c} \in m_{(X, E)}$ such that $\tilde{X}=(A, E)^{c} \cup$ $(B, E)^{c}$. Then, $m_{(X, E)^{-}} \mathrm{Cl}(A, E)^{c} \cap(\mathrm{B}, \mathrm{E})=(\mathrm{A}, \mathrm{E}) \cap m_{(X, E)^{-}} \mathrm{Cl}(B, E)^{c}=(A, E)^{c} \cap$ $(B, E)^{c}=\phi$. This contradicts the hypothesis in (2). This show that (1) is true. Therefore, $(2) \rightarrow(1)$.

Remark 3.8. Let $\left(\mathrm{X}, \tau\right.$,E) be a soft topological space over $\mathrm{X}$, so we put $m_{(X, E)}=\tau$. Then, the following statements are equivalent:

(1) $(\mathrm{X}, \tau, \mathrm{E})$ is a soft connected (soft semi-connected, soft preconnected, soft bconnected) space. 
(2) $(\mathrm{X}, \tau$,E) is not the soft union of any two soft separated (soft semi separated, soft preseparated, soft b-separated) sets.

Remark 3.9. (1) Let $m_{(X, E)}$ be a soft m-structure over $\mathrm{X}$ with the property $\mathbf{B}$, and let $(\mathrm{A}, \mathrm{E})$ be a soft set over $\mathrm{X}$. If $\phi \neq(\mathrm{A}, \mathrm{E}) \subset\left(\mathrm{X}, m_{(X, E)}\right)$ then $(\mathrm{A}, \mathrm{E})$ is a soft $\mathrm{m}$-connected set in $m_{(X, E)}$ whenever $\left(\mathrm{X}, m_{(X, E)}\right)$ is a soft $\mathrm{m}$-connected space.

(2) Let $\left(\mathrm{X}, \tau\right.$,E) be a soft topological space over $\mathrm{X}$, so we put $m_{(X, E)}=\tau$. If $\phi \neq$ $(\mathrm{A}, \mathrm{E}) \subset(\mathrm{X}, \tau, \mathrm{E})$ then $(\mathrm{A}, \mathrm{E})$ is a soft connected (soft semi-connected, soft preconnected, soft b-connected) set over $\mathrm{X}$ whenever $(\mathrm{X}, \tau, \mathrm{E})$ is a soft connected (soft semi-connected, soft preconnected, soft b-connected) space.

Theorem 3.7. Let $m_{(X, E)}$ be a soft $m$-structure over $X$ with the property $\mathbf{B}$. In $\left(X, m_{(X, E)}\right)$, let the soft set $(A, E)$ be a soft m-connected set. Let $(B, E)$ and $(C, E)$ be soft m-separated sets. If $(A, E) \subset(B, E) \cup(C, E)$. Then, either $(A, E) \subset(B, E)$ or $(A, E) \subset(C, E)$.

Proof: Suppose $(\mathrm{A}, \mathrm{E})$ is a soft m-connected set and $(\mathrm{B}, \mathrm{E}),(\mathrm{C}, \mathrm{E})$ are soft $\mathrm{m}$ separated sets such that $(\mathrm{A}, \mathrm{E}) \subset(\mathrm{B}, \mathrm{E}) \cup(\mathrm{C}, \mathrm{E})$. Let $(\mathrm{A}, \mathrm{E})$ notsubset $(\mathrm{B}, \mathrm{E})$ and $(\mathrm{A}, \mathrm{E})$ is not a subset of $(\mathrm{C}, \mathrm{E})$. Suppose $\left(A_{1}, \mathrm{E}\right)=(\mathrm{B}, \mathrm{E}) \cap(\mathrm{A}, \mathrm{E}) \neq \phi$ and $\left(A_{2}, \mathrm{E}\right)$ $=(\mathrm{C}, \mathrm{E}) \cap(\mathrm{A}, \mathrm{E}) \neq \phi$. Then, $(\mathrm{A}, \mathrm{E})=\left(A_{1}, \mathrm{E}\right) \cup\left(A_{2}, \mathrm{E}\right)$. Since $\left(A_{1}, \mathrm{E}\right) \subset(\mathrm{B}, \mathrm{E})$. Hence, $m_{(X, E)}-\mathrm{Cl}\left(A_{1}, \mathrm{E}\right) \subset m_{(X, E)}-\mathrm{Cl}(\mathrm{B}, \mathrm{E})$. Since $m_{(X, E)}-\mathrm{Cl}(\mathrm{B}, \mathrm{E}) \cap(\mathrm{C}, \mathrm{E})=\phi$ then $m_{(X, E)}-\mathrm{Cl}\left(A_{1}, \mathrm{E}\right) \cap\left(A_{2}, \mathrm{E}\right)=\phi$. Since $\left(A_{2}, \mathrm{E}\right) \subset(\mathrm{C}, \mathrm{E})$. Hence, $m_{(X, E)}-\mathrm{Cl}\left(A_{2}, \mathrm{E}\right)$ $\subset m_{(X, E)^{-}} \mathrm{Cl}(\mathrm{C}, \mathrm{E})$. Since $m_{(X, E)^{-}} \mathrm{Cl}(\mathrm{C}, \mathrm{E}) \cap(\mathrm{B}, \mathrm{E})=\phi$. Then $m_{(X, E)^{-}} \mathrm{Cl}\left(A_{2}, \mathrm{E}\right)$ $\cap\left(A_{1}, \mathrm{E}\right)=\phi$. But $(\mathrm{A}, \mathrm{E})=\left(A_{1}, \mathrm{E}\right) \cup\left(A_{2}, \mathrm{E}\right)$. Therefore, $(\mathrm{A}, \mathrm{E})$ is not a soft $\mathrm{m}-$ connected space. This is a contradiction. Then either $(\mathrm{A}, \mathrm{E}) \subset(\mathrm{B}, \mathrm{E})$ or $(\mathrm{A}, \mathrm{E}) \subset$ $(\mathrm{C}, \mathrm{E})$.

Remark 3.10. Let $\left(\mathrm{X}, \tau\right.$,E) be a soft topological space over $\mathrm{X}$, so we put $m_{(X, E)}=$ $\tau$. Also, let $(\mathrm{A}, \mathrm{E})$ be a soft connected (resp. soft semi-connected, soft preconnected, soft b-connected) set. Let $(\mathrm{B}, \mathrm{E})$ and $(\mathrm{C}, \mathrm{E})$ be soft separated (resp. soft semi-separated, soft preseparated, soft b-separated) sets. If $(\mathrm{A}, \mathrm{E}) \subset(\mathrm{B}, \mathrm{E}) \cup(\mathrm{C}, \mathrm{E})$ then either $(\mathrm{A}, \mathrm{E}) \subset(\mathrm{B}, \mathrm{E})$ or $(\mathrm{A}, \mathrm{E}) \subset(\mathrm{C}, \mathrm{E})$.

Let $m_{(X, E)}$ be a soft m-structure over $\mathrm{X}$ with the property B. In $\left(\mathrm{X}, m_{(X, E)}\right)$, let the soft set $(\mathrm{A}, \mathrm{E})$ be a soft m-connected set, then $m_{(X, E)}-\mathrm{Cl}(\mathrm{A}, \mathrm{E})$ is soft mconnected.

Proof: Suppose the soft set $(\mathrm{A}, \mathrm{E})$ is a soft m-connected set and $m_{(X, E)}-\mathrm{Cl}(\mathrm{A}, \mathrm{E})$ is not. Then there exist two soft m-separated sets $(\mathrm{B}, \mathrm{E})$ and $(\mathrm{C}, \mathrm{E})$ such that $m_{(X, E)^{-}}$ $\mathrm{Cl}(\mathrm{A}, \mathrm{E})=(\mathrm{B}, \mathrm{E}) \cup(\mathrm{C}, \mathrm{E})$. But $(\mathrm{A}, \mathrm{E}) \subset m_{(X, E)}-\mathrm{Cl}(\mathrm{A}, \mathrm{E})$, then $(\mathrm{A}, \mathrm{E})=(\mathrm{B}, \mathrm{E}) \cup(\mathrm{C}, \mathrm{E})$ and since $(\mathrm{A}, \mathrm{E})$ is a soft $\mathrm{m}$-connected set, then by Theorem 3.7 either $(\mathrm{A}, \mathrm{E}) \subset(\mathrm{B}, \mathrm{E})$ or $(\mathrm{A}, \mathrm{E}) \subset(\mathrm{C}, \mathrm{E})$.

(i) If $(\mathrm{A}, \mathrm{E}) \subset(\mathrm{B}, \mathrm{E})$ then $m_{(X, E)^{-}} \mathrm{Cl}(\mathrm{A}, \mathrm{E}) \subset m_{(X, E)^{-}} \mathrm{Cl}(\mathrm{B}, \mathrm{E})$. But $m_{(X, E)^{-}}$ $\mathrm{Cl}(\mathrm{B}, \mathrm{E}) \cap(\mathrm{C}, \mathrm{E})=\phi$. Hence, $m_{(X, E)^{-}} \mathrm{Cl}(\mathrm{A}, \mathrm{E}) \cap(\mathrm{C}, \mathrm{E})=\phi$. Since $(\mathrm{C}, \mathrm{E}) \subset m_{(X, E)^{-}}$ $\mathrm{Cl}(\mathrm{A}, \mathrm{E})$, then $(\mathrm{C}, \mathrm{E})=\phi$ this is a contradiction.

(ii) If $(\mathrm{A}, \mathrm{E}) \subset(\mathrm{C}, \mathrm{E})$ then in the same way we can prove that $(\mathrm{B}, \mathrm{E})=\phi$, which is a contradiction. Therefore, $m_{(X, E)}-\mathrm{Cl}(\mathrm{A}, \mathrm{E})$ is soft m-connected. 
Remark 3.11. Let $(\mathrm{X}, \tau, \mathrm{E})$ be soft topological space over $\mathrm{X}$, we put $m_{(X, E)}=\tau$ let soft set $(\mathrm{A}, \mathrm{E})$ be a soft connected (resp. soft semi connected,soft pre connected, soft bconnected)set then $m_{(X, E)}-\mathrm{Cl}(\mathrm{A}, \mathrm{E})$ is soft connected(resp. soft semi connected,soft pre connected, soft b-connected).

Theorem 3.8. Let $m_{(X, E)}$ be a soft $m$-structure over $X$ with the property $\mathbf{B}$. In $\left(X, m_{(X, E)}\right)$, let the soft set $(A, E)$ be a soft m-connected set and $(A, E) \subset(B, E) \subset$ $m_{(X, E)}-C l(A, E)$ then $(B, E)$ is soft m-connected.

Proof: If $(\mathrm{B}, \mathrm{E})$ is not soft m-connected, then there exist two soft sets $(\mathrm{C}, \mathrm{E})$ and $(\mathrm{D}, \mathrm{E})$ such that $m_{(X, E)}-\mathrm{Cl}(\mathrm{C}, \mathrm{E}) \cap(\mathrm{D}, \mathrm{E})=(\mathrm{C}, \mathrm{E}) \cap m_{(X, E)}-\mathrm{Cl}(\mathrm{D}, \mathrm{E})=\phi$ and $(\mathrm{B}, \mathrm{E})=(\mathrm{C}, \mathrm{E}) \cup(\mathrm{D}, \mathrm{E})$. Since $(\mathrm{A}, \mathrm{E}) \subset(\mathrm{B}, \mathrm{E})$, thus either $(\mathrm{A}, \mathrm{E}) \subset(\mathrm{C}, \mathrm{E})$ or $(\mathrm{A}, \mathrm{E})$ $\subset(\mathrm{D}, \mathrm{E})$. Suppose $(\mathrm{A}, \mathrm{E}) \subset(\mathrm{C}, \mathrm{E})$ then $m_{(X, E)} \mathrm{Cl}(\mathrm{A}, \mathrm{E}) \subset m_{(X, E)}-\mathrm{Cl}(\mathrm{C}, \mathrm{E})$, thus $m_{(X, E)}-\mathrm{Cl}(\mathrm{A}, \mathrm{E}) \subset(\mathrm{D}, \mathrm{E})=m_{(X, E)^{-}} \mathrm{Cl}(\mathrm{C}, \mathrm{E}) \subset(\mathrm{D}, \mathrm{E})=\phi$. But $(\mathrm{D}, \mathrm{E}) \subset(\mathrm{B}, \mathrm{E}) \subset$ $m_{(X, E)}-\mathrm{Cl}(\mathrm{A}, \mathrm{E})$, thus $m_{(X, E)} \mathrm{Cl}(\mathrm{A}, \mathrm{E}) \cap(\mathrm{D}, \mathrm{E})=(\mathrm{D}, \mathrm{E})$. Therefore, $(\mathrm{D}, \mathrm{E})=\phi$ which is a contradiction. Thus, $(\mathrm{B}, \mathrm{E})$ is a soft m-connected set.

If $(\mathrm{A}, \mathrm{E}) \subset(\mathrm{B}, \mathrm{E})$, then we can prove that $(\mathrm{C}, \mathrm{E})=\phi$. This is a contradiction. Then $(\mathrm{B}, \mathrm{E})$ is soft $\mathrm{m}$-connected.

Remark 3.12. Let $(\mathrm{X}, \tau, \mathrm{E})$ be a soft topological space over $\mathrm{X}$, so we put $m_{(X, E)}$ $=\tau$. Also, let the soft set $(\mathrm{A}, \mathrm{E})$ be a soft connected (resp. soft semi-connected, soft preconnected, soft b-connected) set and $(\mathrm{A}, \mathrm{E}) \subset(\mathrm{B}, \mathrm{E}) \subset m_{(X, E)}-\mathrm{Cl}(\mathrm{A}, \mathrm{E})$, then $(\mathrm{B}, \mathrm{E})$ is soft connected (resp. soft semi-connected, soft preconnected, soft b-connected).

Remark 3.13. Let $(X, \tau, E)$ be a soft topological space over $X$, and $(F, E)$ be a soft set over $\mathrm{X}$. (X, $\tau, \mathrm{E})$ is soft connected (soft semi-connected, soft preconnected, soft b-connected) if and only if there does not exist nonempty soft set $(\mathrm{F}, \mathrm{E})$ over $\mathrm{X}$ which is both soft open (resp. soft semi-open, soft preopen, soft b-open) and soft closed (resp. soft semi-closed, soft pre-closed, soft b-closed) set over X.

\section{REF E R E N C ES}

1. U. Acar, F. Koyuncu and B. Tanay: Soft sets and soft rings. Comput. Math. Appl. ,59, (2010),pp. 3458-3463.

2. M. Akdag and A. Ozkan : On soft preopen sets and soft pre separation axioms.Gazi University Journal of Science GU J Sci., 27(4), (2014),pp. 1077-1083.

3. M. Akdag and A. OzKan: On soft $\alpha$-open sets and soft $\alpha$-continuous functions. Abstract and Applied Analysis http//dx.doi.org/101155/2014/891341 2014 Article ID 891341 (2014) 7 pages.

4. M. Akdag and A. Ozkan: On soft $\beta$-open sets and soft $\beta$-continuous functions. The Scientific World Journal 2014 Article ID 843456 (2014) 6 pages.

5. M. Akdag and A. OzKan : soft b-open sets and soft b-continuous functions. Math. Sci 8:124 DOI 10.1007/s40096-014-0124-7 (2014).

6. I. Arockiarani and A. Arokialancy :Generalized soft $\mathrm{g} \beta$-closed sets and soft gs $\beta$-closed sets in soft topological spaces. Int. J. Math. Arch.,4(2), (2013),pp. 1-7. 
7. M. Irfan Ali, F. Feng, X. Liu, W. K. Min and M. Shabir: On some new operations in soft set theory. Comput. Math. Appl.,57, (2009),pp. 1547-1553.

8. B. Chen: Soft semi-open sets and related properties in soft topological spaces. Applied Mathematics and Information Sciences ,7(1) ,(2013),pp. 287-294.

9. D.N.Georgiou, A.C.Megaritis and V.I.Petropoulos: On soft topological spaces. Applied Mathematics and Information Sciences,7, (2013),pp. 1889-1901.

10. H.Hazra , P.Majumdar and S.K.Samanta: Soft topology. Fuzzy Inf. Eng., DOI 10, (2012),pp.105-115.

11. SAbir Hussain: $A$ note on soft connectedness. Journal of the Egyptian Math ematical Society ,23, (2015) ,pp.6-11.

12. A. Kharal and B. Ahmad: Mappings on soft classes. New Math. Nat. Comput., 7 (3), (2011) ,pp. 471-481.

13. A. Kandil, O. A. E. Tantawy, S. A. El-Sheikh and A. M. Abd El-latif : gammaoperation and decompositions of some forms of soft continuity in soft topological spaces. Annals of Fuzzy Mathematics and Informatics, 7, (2014),pp. 181-196.

14. FUCAI Lin: Soft connected space and soft paracompact space. International Journal of Mathematical, Physical, Electrical and Computer Enginnering, 7 (2), (2013),pp. 277-283.

15. P.K. MAJI, R. Biswas and R. Roy: An application of soft sets in decision making problem. Comput. Math. Appl. ,44, (2002),pp. 1077-1083.

16. P.K. Maji, R. Biswas and R. Roy: Soft set theory. Comput. Math Appl. ,45, (2003),pp. 555-562.

17. J. Mahanta and P. K. Das: On soft topological space via semi open and semi closed soft sets. Kyungpook Math. J.,54, (2014),pp. 221-236.

18. W. K. Min: A note on soft topological spaces. Computers and Mathematics with Applications ,62 ,(2011),pp. 3524-3528.

19. D. Molodtsov: Soft set theory first results. Comput. Math. Appl.,37, (1999),pp. 9-31.

20. E. Peyghan ,B. Samadi and A. Tayebi: On soft connectedness. arXiv:1202.1668v1 [math.GN]8Feb (2012).

21. S. S. Thakur and Alpa Singh Rajput: On Soft M-continuous Mappings. The Journal of Fuzzy Mathematics, Los Angeles, 25, (2017),pp. 313-326.

22. M. Shabir and M. NAz: On soft topological spaces. Comput. Math. Appl.,61, (2011),pp. 1786-1799.

23. Q. M. Sun, Z. L. Zhang and J. Liu: In proceedings of rough sets and knowledge technology. Third International Conference. RSKT 2008, (17-19), (2008),pp. 403409.

24. J. Subhashinin and C. Sekar : Soft p-connectedness via soft p-open sets. International Journal of Mathematical Trends and Technology (IJMTT). V6:203-214, ISSN:2231-5373

25. I. Zorlutuna, N. Akdag W.K. Min and S. Atmaca: Remarks on soft topological spaces. Ann Fuzzy Math. Inf.,3 (2), (2012),pp. 171-185.

26. I. Zorlutuna and H. ÇAKIR:On continuity of soft mappings. Appl. Math. Inf. Sci.,9(1),(2015),pp. 403-409. 
S.S. thakur

Faculty of Science

Department of Applied Mathematics

P. O. Box 60

Jabalpur Engineering College, Jabalpur (M. P.) 482011 India

samajh_singh@rediffmail.com

Alpa Singh Rajput

Department of Mathematics

P.O. Box 73

Jabalpur Engineering College, Jabalpur (M. P.) 482011 India

alpasinghrajput09@gmail.com 